\title{
Geleitwort von Bundesminister Hermann Gröhe (1. Auflage)
}

Liebe Leserinnen und Leser,

wer bei uns krank wird oder einen Unfall erleidet, kann sich auf unser Gesundheitswesen verlassen. Zuverlässig und leistungsstark sorgt es dafür, dass alle Menschen die für sie notwendige Behandlung erhalten.

Ein unabdingbares Qualitätsmerkmal ist dabei die Patientensicherheit. Sie steht daher besonders im Blickpunkt der Gesundheitspolitik. So hat die Bundesregierung in den vergangenen 15 Jahren verstärkt rechtliche Rahmenbedingungen für Qualitätssicherung und Patientensicherheit geschaffen oder weiterentwickelt. Ein wichtiger Baustein hierbei ist etwa das 2013 in Kraft getretenen Patientenrechtegesetz.

Für den Erhalt unseres guten Gesundheitswesens unverzichtbar sind Maßnahmen, die dazu beitragen, die Sicherheit so zu verstärken, dass Fehler möglichst gar nicht erst entstehen. Dabei stehen heute vor allem die Möglichkeiten der Fehlervermeidung und der Sicherheitskultur im Fokus - und nicht mehr allein die Frage der Schuld. Diese Entwicklung spiegelt sich auch in den Beiträgen des Ihnen vorliegenden Buches wider. Besonders die Ausführungen zum „Faktor Mensch im Patientensicherheits-Management“, aber auch die Themenfelder „Kommunikation“ und „Risikomanagement als lernendes System“ sowie nicht zuletzt die „Einbeziehung der Sicht von Patientinnen und Patienten“ sind nicht nur interessante Kapitel der vorliegenden Veröffentlichung, sondern auch unverzichtbare Bausteine, um die Patientensicherheit in unserem Gesundheitswesen weiter voranzubringen.

Das vorliegende Buch bietet somit nicht nur einen guten Überblick über die Herausforderungen, die dieses Thema für Sie als Ärztinnen und Ärzte und Angehörige anderer Gesundheitsberufe mit sich bringt. Dank praxisnaher Tipps und Checklisten ist es auch eine gute Hilfestellung für Ihren Arbeitsalltag. Ich wünsche Ihnen, liebe Leserinnen und Leser, eine interessante Lektüre und viele neue Erkenntnisse!

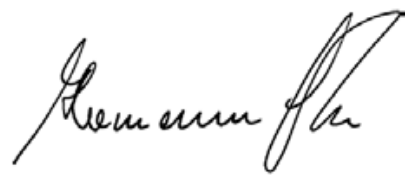

Hermann Gröhe

Bundesminister

Mitglied des Deutschen Bundestages 
